\title{
Evaluation of Enzyme Kinetic Parameters to Produce Methanol Using Michaelis-Menten Equation
}

\author{
Norazwina Zainol*, Siti Natrah Ismail \\ Faculty of Chemical \& Natural Resources Engineering, Universiti Malaysia Pahang, \\ 26300 Gambang, Pahang, Malaysia
}

Received: 1st October 2018; Revised: $26^{\text {th }}$ January 2019; Accepted: $2^{\text {nd }}$ February 2019; Available online: 30th April 2019; Published regularly: 1't August 2019

\begin{abstract}
Determination of kinetic parameters of enzymes is important in biotechnology research. It is also one of the most challenging processes in methanol production. The activity of enzyme is determined in term of initial rates at various substrate concentrations. The enzymatic hydrolysis of methanol by pectin methyl esterase (PME) enzyme was investigated at $25^{\circ} \mathrm{C}$ and $\mathrm{pH} 9$ over the reaction time range from 0 to $90 \mathrm{~min}$. In this study, the parameters of the enzyme's kinetic, $K_{M}$ and $V_{\max }$ were directly determined using a modified Michaelis-Menten equation by applying the Lineweaver-Burk plots. Besides, nonlinear regression of Michaelis-Menten equation was calculated based on Euler's and Runge-Kutta $4^{\text {th }}$ order methods by using Solver supplement application. The result of kinetic constant was tested by comparing the experimental data with model predictions. It was found that Euler and Runge-Kutta method was successful in determining the kinetic parameter rather than Lineweaver-Burk plot. The application of the Michaelis-Menten equation describes the enzyme kinetic very well. From the kinetic analysis, it showed the good agreement between the result obtained and the predictions model in the production of methanol using PME enzyme. Copyright (C) 2019 BCREC Group. All rights reserved
\end{abstract}

Keywords: Methanol; Pectin methyl esterase; Michaelis-Menten equation; Enzymatic reaction; RungeKutta method

How to Cite: Zainol, N., Ismail, S.N. (2019). Evaluation of Enzyme Kinetic Parameters to Produce Methanol Using Michaelis-Menten Equation. Bulletin of Chemical Reaction Engineering \& Catalysis, 14(2): 436-442 (doi:10.9767/bcrec.14.2.3317.436-442)

Permalink/DOI: https://doi.org/10.9767/bcrec.14.2.3317.436-442

\section{Introduction}

The depletion of fossil fuel supply has triggered the application of biomass as an alternative and renewable source of fuel and energy [1]. Biomass can be converted to methanol that widely used as alternative fuel for internal combustion and other engines, either in combination with gasoline or directly. Besides, methanol also can be used as solvent for the extraction process [2].

* Corresponding Author.

E-mail: azwina@ump.edu.my (N. Zainol)
Industrial crop, forest and forage residues were the examples of biomass that commonly used to produce methanol. Pectin methyl esterase (PME) enzyme was used to convert the pectin from biomass residues to methanol. The enzymatic hydrolysis of biomass by using pectin methyl esterase (PME) enzyme can be done to produce methanol [3]. The used of enzyme can enhance the rate of biochemical reactions [4].

Determination of kinetic parameters for the enzyme activity is one of the most challenging processes in methanol production. The activity of enzyme is determined in term of initial rates at different concentration of substrate and time- 
course reaction analysis [5]. The analysis of reaction over time provides information about the enzyme properties in a single experiment. The kinetic data provide information about the initial substrate concentration, the concentration between the time interval and the end of concentration after the reaction process. The problem in enzymatic hydrolysis can be classified into three classes which are the activity of enzyme, the complexity of substrate and the interaction of enzyme-substrate [6]. The most popular mechanistic model for simple enzyme kinetics was developed by V.C.R. Henri in 1902 and by L. Michaelis and M.L. Menten in 1913. Kinetics of simple enzyme-catalyzed reactions is often referred as Michaelis-Menten kinetics [7]. In this model, the single-substrate-enzymecatalyzed reaction involves a reversible step for enzyme-substrate complex formation and a dissociation step of the enzyme-product complex. The process is represented schematically by the Equation 1. This equation describes the enzymatic equation between the substrate and the product that produce during the reaction process [8].

$$
\mathrm{E}+\mathrm{S} \leftrightarrow \mathrm{ES} \rightarrow \mathrm{P}+\mathrm{E}
$$

From the equation, $E$ represents the enzyme, $S$ is a substrate, and $E S$ is an enzyme-substrate complex that may generate or dissociate a product $P$ and release the enzyme. MichaelisMenten equation (Equations 2 and 3) was used to determine the value of $K_{M}$ and $V_{\max }$ for the activity of enzyme.

$$
\begin{aligned}
& \frac{d S}{d t}=K_{M}[S] \\
& \frac{d P}{d t}=\frac{V_{\max }[S]}{K_{M}+[S]}
\end{aligned}
$$

These equations could be linearized and rearranged to obtain Equation 4 [9].

$$
\frac{1}{[V]}=\frac{K_{M}}{V_{\max }} \times \frac{1}{[S]}+\frac{1}{V_{\max }}
$$

The determination of values for $K_{M}$ and $V_{\max }$ can be obtained by a series of initial-rate experiments with different initial substrate concentration. In these experiments, known amount of substrate $\left[S_{0}\right]$ and enzyme $\left[E_{0}\right]$ were mixed and the initial reaction rates were measured. Using the initial substrate concentration as $[S]$, a linear plot of $1 / V$ versus $1 / S$, named Doublereciprocal plot or Lineweaver-Burk plot can be obtained. The intercept of the plot is $1 / V_{\max }$ and the slope of the plot is $K_{M} / V_{\max }$. Once $V_{\max }$ is known, $K_{M}$ can be calculated [10], however Lineweaver-Burk plot could only solve MichaelisMenten equation involving high reaction veloci- ty problem. With low reaction velocity, the reciprocal transformation introduces higher errors and linear regression would not be suitable to analyze the data. To date, no paper has been reporting on the application of non-linear method to solve the Michaelis-Menten equation.

This study compared the determination of enzyme kinetic parameters ( $K_{M}$ and $V_{\max }$ ) using the conventional Lineaweaver-Burke plot and non-linear method (Euler's and Runge-Kutta $4^{\text {th }}$ order methods). In this methanol production, the lime peel juice is $E$ that contained PME enzyme, the pectin solution is $S$, and the various methanol concentration are $P$, and $v$ is the reaction velocity.

\section{Materials and Methods}

\subsection{Extraction of PME from Lime Peel}

Lime fruits were purchased at a local supermarket. The limes were peeled to obtain the peels. The extraction of PME enzyme was done by suspending the lime peels into $5 \mathrm{M} \mathrm{NaCl}$ solution. The ratio between the peels and $\mathrm{NaCl}$ solution was 1:4 (w/v). The centrifugal juice extractor was used to extract the peel for $1 \mathrm{~min}$. The supernatant was filtered through cheesecloth (grade 80) and then centrifuged at $3000 \mathrm{~g}$ [11]. It was centrifuged for $15 \mathrm{~min}$ at temperature of $4{ }^{\circ} \mathrm{C}$.

\subsection{Preparation of Pectin Solution}

The pectin solution was prepared at the concentration of $0.5 \%$. The solution was prepared by diluting the pectin into $0.3 \mathrm{M} \mathrm{NaCl}$ solution. The solution was heated at $100{ }^{\circ} \mathrm{C}$ on the hot plate. The solution was stirred until the pectin completely diluted in $\mathrm{NaCl}$ solution [12].

\subsection{Experimental Procedure to Produce Metha- nol}

The methanol was produced by mixing 10 $\mathrm{mL}$ of the extracted lime peel juice that contained PME enzyme with $90 \mathrm{~mL}$ pectin solution. For the pectin solution, the $\mathrm{pH}$ value was adjusted to 9 using $\mathrm{NaOH}$. Then, the extracted lime peel juice was mixed with the pectin solution. The sample was put in the incubator shaker. The temperature for the incubator shaker was controlled at $25^{\circ} \mathrm{C}$ and agitation at $150 \mathrm{rpm}$. Samples for analysis were collected for every $10 \mathrm{~min}$ for $90 \mathrm{~min}$ [13].

\subsection{Methanol Analysis by Using HPLC}

The samples were filtered using nylon syringe filter $(0.45 \mu \mathrm{m}$, Millipore) and it was in- 
jected into vials. High performance liquid chromatography (HPLC) (Agilent Series 1200) was used to analyze the composition of methanol in the samples. Agilent Hi-Plex H $(8 \%$ crosslinked) $(7.7 \times 300 \mathrm{~mm}, 8 \mu \mathrm{m})$ was used in the analysis. The mobile phase that used for the analysis was water and it was set at 0.6 $\mathrm{mL} / \mathrm{min}$ for the flow rate. The retention time between the samples and methanol standards were compared in order to determine the methanol contents [14].

\subsection{Determination of Degree of Esterification}

Titration method was applied to determine the degree of esterification (DE) of pectin [15]. The pectin sample $(0.5 \mathrm{~g})$ was dissolved with 2 $\mathrm{mL}$ of ethanol and $20 \mathrm{~mL}$ of distilled water. Five drops of phenolphthalein reagent were added to the solution after the pectin sample completely dissolved. The solution was titrated using $0.1 \mathrm{M} \mathrm{NaOH}\left(V_{1}\right)$ until it changed to pale pink colour. Then, $10 \mathrm{~mL}$ of $\mathrm{NaOH}(0.5 \mathrm{M})$ was added for the hydrolysis process. After $20 \mathrm{~min}$, $10 \mathrm{~mL}$ of $0.5 \mathrm{M} \mathrm{HCl}$ was added and stirred until colour of the solution changed to colourless. After that, five drops of phenolphthalein reagent was added into the solution and $0.1 \mathrm{M}$ $\mathrm{NaOH}\left(V_{2}\right)$ was titrated until the solution changed to pale pink colour. Equation 5 was used to calculate the DE of pectin where $V_{1}$ and $V_{2}$ were initial and final volume of $0.1 \mathrm{M}$ $\mathrm{NaOH}$, respectively.

$$
\% D E=\frac{V_{2}}{V_{1}+V_{2}} \times 100
$$

\subsection{Determination of Kinetic Parameters}

Michaelis-Menten equation (Equations 2 and 3) was used to determine the value of $K_{M}$

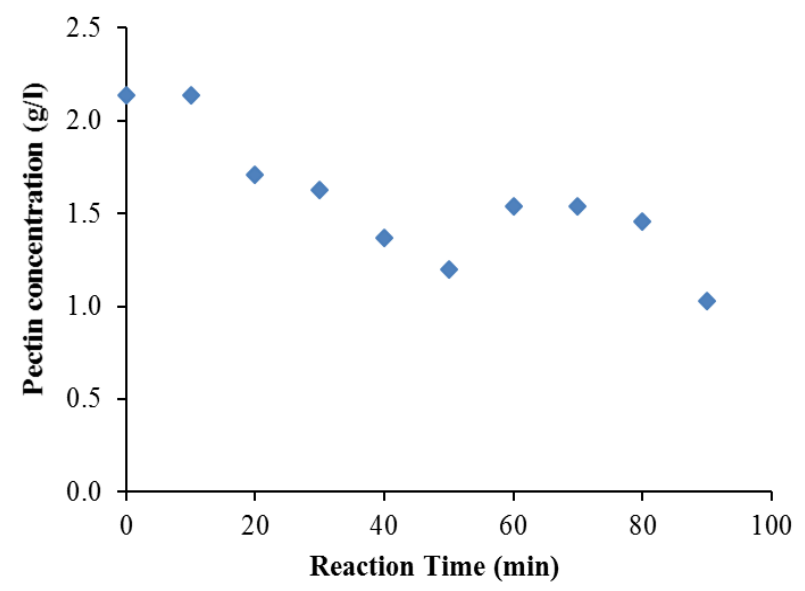

Figure 1. Experimental values of pectin concentration in 90 minutes reaction and $V_{\max }$ for the activity of PME enzyme. Conventionally, the $K_{M}$ and $V_{\max }$ values were determined using Lineweaver-Burk plot. Equation 6 was obtained by rearranging the MichaelisMenten equation [9]. The plot was done by plotting the inverse initial velocity $(1 / V)$ versus inverse substrate concentration $(1 / S)$.

$$
\frac{1}{[V]}=\frac{K_{M}}{V_{\max }} \times \frac{1}{[S]}+\frac{1}{V_{\max }}
$$

In this study, Euler's and Runge-Kutta $4^{\text {th }}$ order methods also used to solve the Equations 2 and 3 in order to determine the values of $K_{M}$ and $V_{\max }$. The experimental data were fitted to both equations and solved using Solver that included in Microsoft Office Excel. The correlation coefficient $\left(\mathrm{R}^{2}\right)$ was determined to measure how close the set of data to the theoretical kinetic curve.

\section{Results and Discussion}

\subsection{Reduction of Pectin Concentration}

Figure 1 shows the pectin concentration was decreasing from $2.1 \mathrm{~g} / \mathrm{L}$ to $1.0 \mathrm{~g} / \mathrm{L}$ after 90 minutes reaction with the PME enzyme. The figure showed the concentration of pectin was decreased with the increase of reaction time. The reduction of pectin concentration was considered to be expected because the PME enzyme was capable to hydrolyze pectin to produce methanol and pectic acid [3].

\subsection{Methanol Concentration}

Figure 2 shows the concentration of methanol was increased when the reaction time increased. The high amount of product was formed when the enzyme was incubated with the substrate for longer reaction time. The con-

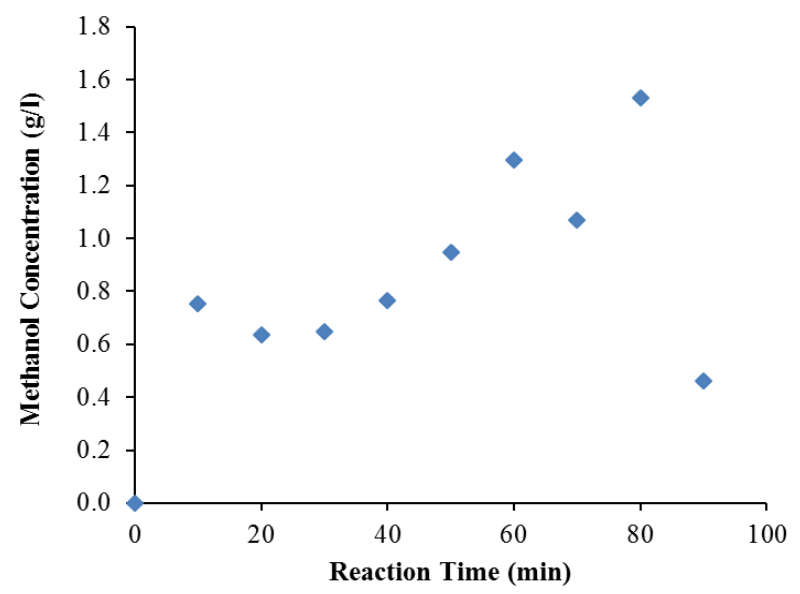

Figure 2. Experimental values of methanol concentration in 90 minutes reaction 
centration of methanol increased due to the demethylation of pectin by PME enzyme [16]. The biological breakdown of pectin is catalyzed by the PME enzymes. PME enzyme capable to hydrolyze the ester that presents in the pectin backbone and release methanol [17]. The reaction of PME enzyme was occurred according to the double-displacement mechanisms.

The deesterification of pectin starts from the reducing end of pectin chain or nears the free carboxyl group [18]. The deesterification occurred by transfer the $\mathrm{C}_{6}$ carboxyl group in pectin-PME complexes to water molecules. It altered the degree and pattern of methyl esterification and transacylation through transferring the $\mathrm{C}_{6}$ carboxyl groups to the hydroxyl groups of another pectin molecules and resulting in the formation of high molecular weight pectins with new non-methoxy ester linkages. The activity of enzyme capable to remove the methoxy group and produce free carboxylic radical [12]. However, the formation rate of the product is not a simple linear function of the reaction time.

\subsection{Lineweaver-Burk Plot}

Michaelis-Menten equation was used to estimate the kinetic parameters from the result that obtained from the experiment. The Michaelis-Menten equation was rearranged into a linear equation by taking the reciprocal of both sides as shown in Equation 5. Figure 3 shows the Lineweaver-Burk plot of PME enzyme ac-

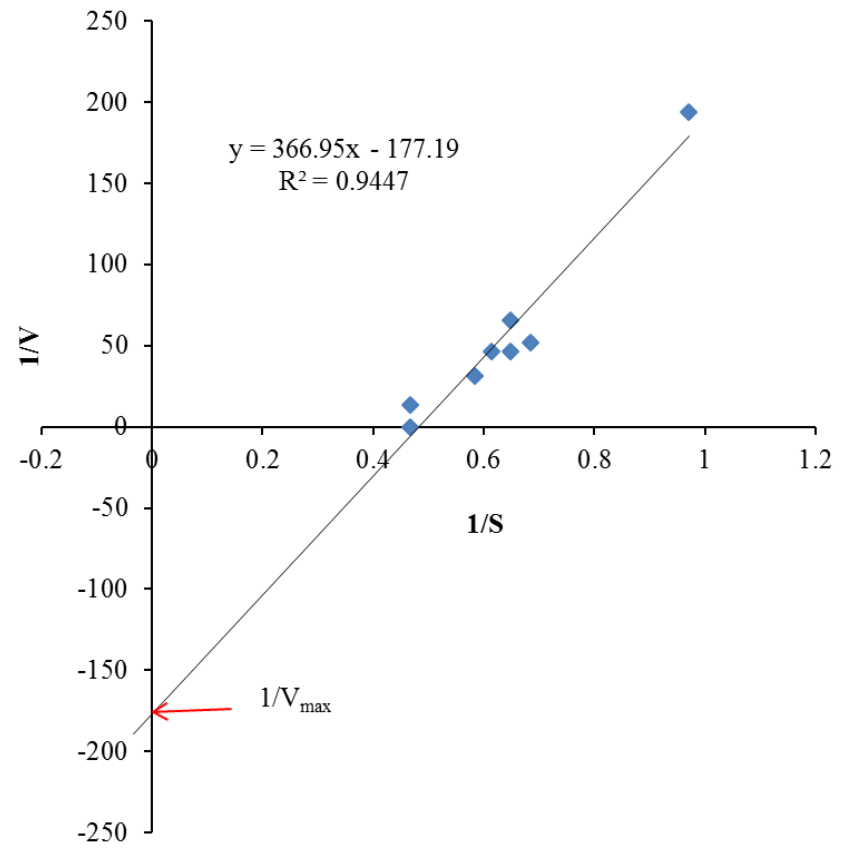

Figure 3. Lineweaver-Burk plot to determine $K_{M}$ and $V_{\max }$ of PME enzyme tivity. The intercept of the straight line was used to determine the values of $V_{\max }$ and $K_{M}$ which the y-intercept and slope represent the $1 / V_{\max }$ and $K_{M} / V_{\max }$, respectively [20]. The $K_{M}$ value that obtained from the plot was $-2.07 \mathrm{~g} / \mathrm{l}$ while $V_{\max }$ was $-0.006 \mathrm{~g} / \mathrm{l}$. The negative values for both kinetic constants are probably caused by the fact that enzyme was saturated at low substrate concentrations [21]. According to Dhatt and Bhattacharyya [22], by employing Lineweaver Burk plot, the lowest substrate concentrations, which often have the greatest error, have more influence on the slope than the highest ones. The reciprocal transformation introduces errors that are much higher at low substrate concentrations of substrate and linear regression should not be used to analyze the data. Therefore non-linear regression should be employed to fit the data to the MichaelisMenten equation instead.

\subsection{Euler's and Runge-Kutta $4^{\text {th }}$ Order}

The values of kinetic parameters also determined using Euler's and Runge-Kutta $4^{\text {th }}$ order methods. Euler's method is a numerical method to solve first order first degree differential equation with a given initial value. It is the most basic explicit method for numerical integration of ordinary differential equations and is the simplest Runge-Kutta method while Runge-Kutta $4^{\text {th }}$ order meaning that the local truncation error is on the order of $\mathrm{O}\left(\mathrm{h}^{5}\right)$, while the total accumulated error is order $\mathrm{O}\left(\mathrm{h}^{4}\right)$. The values of $K_{M}$ and $V_{\max }$ were estimated by solving Equations 2 and 3 concerning the substrate concentration and product formation based on Euler's and Runge-Kutta $4^{\text {th }}$ order methods by using Microsoft Office Excel [23]. In this study, pectin was used as the substrate while the product that produced was methanol.

The initial values for pectin concentration and methanol concentration were $2.14 \mathrm{mg} / \mathrm{L}$ and $0 \mathrm{mg} / \mathrm{L}$, respectively. The experimental data were fitted to Michaelis Menten equation (Equations 3 and 4) using least squares regression. The kinetic constants were determined by minimizing the sum of squared residuals which was the difference between an experimental value, and the predicted value provided by Michaelis-Menten equation [6]. By using Euler's and Runge-Kutta $4^{\text {th }}$ order methods, the predicted value of substrate and product could be calculated. Microsoft Excel Solver was utilized in this calculation to minimize the sum of squared residuals while getting the kinetic constant that would fit the data to MichaelisMenten equation. 
The kinetic calculation from both methods shows the $K_{M}$ value was $2.08 \mathrm{~g} / \mathrm{l}$ while $V_{\max }$ was $0.04 \mathrm{~g} / \mathrm{l}$. The $K_{M}$ was identified when the substrate concentration at half of the maximal rate $\left(V_{\max }\right)$ [24]. The value of $K_{M}$ represents the strength or affinity of binding between the substrate and enzyme. The affinity was greater when the value of $K_{M}$ low and the concentration of substrate that need to achieve the reaction rate also low. The value of $V_{\max }$ that obtained in this study depends on the substrate used, the concentration of salt, reaction temperature and $\mathrm{pH}$ of reaction. The value of $V_{\max }$ that obtained in this study was very low and it showed high affinity of the substrate [25].

Table 1. Predicted values for pectin and methanol concentration

\begin{tabular}{cccccc}
\hline & \multicolumn{2}{c}{$\begin{array}{c}\text { Pectin } \\
\text { Concentration }\end{array}$} & & \multicolumn{2}{c}{$\begin{array}{c}\text { Methanol } \\
\text { Concentration }\end{array}$} \\
\cline { 2 - 3 } \cline { 5 - 6 } Timennnnn & Euler's & $\begin{array}{c}\text { RK 4 } \\
\text { Orh }\end{array}$ & & Euler's & $\begin{array}{c}\text { RK 4 } \\
\text { Order }\end{array}$ \\
\hline 0 & 2.14 & 2.14 & & 0.00 & 0.00 \\
10 & 1.93 & 1.94 & & 0.20 & 0.22 \\
20 & 1.73 & 1.75 & & 0.39 & 0.44 \\
30 & 1.56 & 1.59 & & 0.58 & 0.65 \\
40 & 1.40 & 1.43 & & 0.75 & 0.85 \\
50 & 1.26 & 1.30 & & 0.91 & 1.05 \\
60 & 1.14 & 1.17 & & 1.06 & 1.24 \\
70 & 1.02 & 1.06 & & 1.20 & 1.43 \\
80 & 0.92 & 0.96 & & 1.33 & 1.61 \\
90 & 0.83 & 0.87 & & 1.46 & 1.79 \\
\hline
\end{tabular}

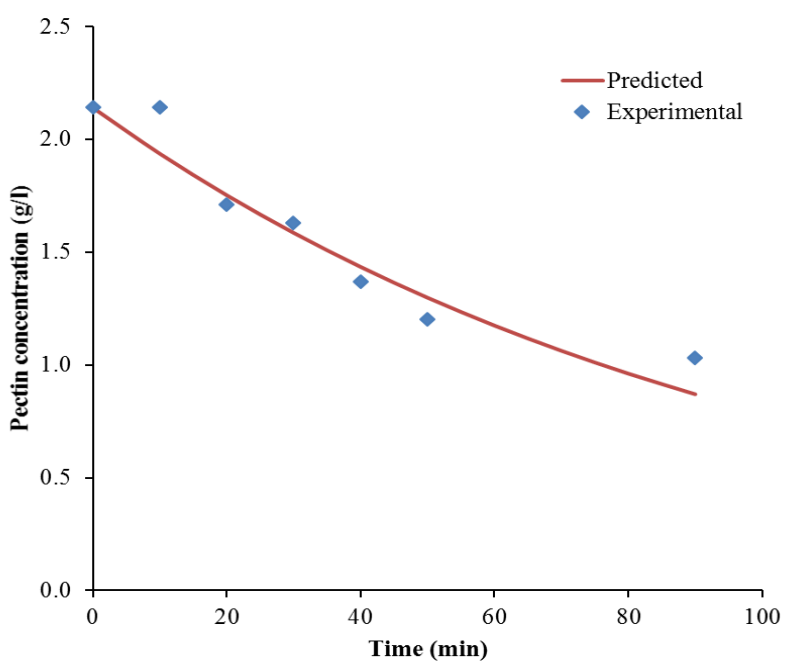

Figure 4. Experimental and predicted values of pectin concentration
3.5 Experimental and Predicted Values of Pectin and Methanol

The application of Euler's and Runge-Kutta $4^{\text {th }}$ order methods capable to calculate the predicted values for pectin and methanol concentrations. Table 1 shows the predicted values obtained when calculated using both methods. Figure 4 and 5 shows the experimental and predicted values that calculated using RungeKutta $4^{\text {th }}$ order method. The experimental and predicted values for the concentration of substrate that used in methanol production is showed in Figure 4. The figure shows the concentration of pectin was decreased with the increase of reaction time. This due to the demethylation of pectin by PME enzyme [26]. The predicted values were observed to be in good agreement with the experimental values with the $\mathrm{R}^{2}$ was 0.90 .

Figure 5 shows the methanol concentration that produces during the experimental and predicted values versus the reaction time. The predicted values are very close to those measured by experiment and the $\mathrm{R}^{2}$ was 0.91 . From Figure 2, it shows the concentration of methanol was increased when the reaction time increased. The concentration of methanol increased due to the activity of PME that catalyzed the $\mathrm{C}-\mathrm{O}$ bond hydrolysis of the methoxylester groups of pectin to form methanol and converted the pectin into pectate [13].

\section{Conclusion}

The major problem to produce methanol using PME enzyme is the lack of kinetic data. The kinetic parameters were determined based

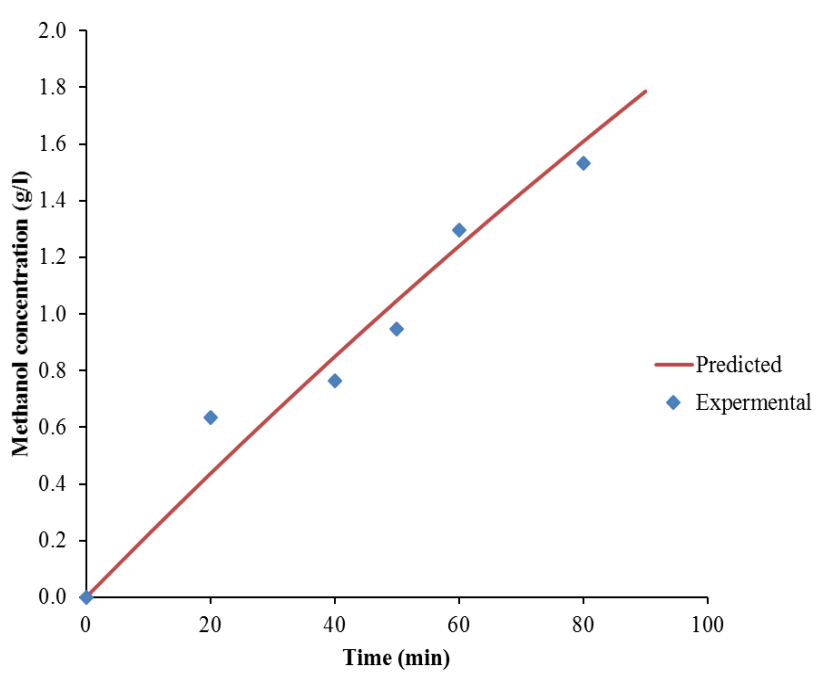

Figure 5. Experimental and predicted values of methanol concentration 
on Michaelis-Menten equation. The parameters were calculated using Lineweaver-Burk plot, Euler's and Runge-Kutta $4^{\text {th }}$ order methods. The values of $K_{M}$ and $V_{\max }$ were measured depending on the pectin and methanol concentrations based on time series data measurements. The $K_{M}$ and $V_{\max }$ values that obtained from Lineweaver-Burk plot were $-2.07 \mathrm{~g} / \mathrm{L}$ and -0.006 $\mathrm{g} / \mathrm{L}$ respectively which showed that application of Lineweaver-Burk plot to solve MichaelisMenten equation was not suitable since the methanol production in this study involved low reaction rate and product concentration. The values that obtained using Euler's and RungeKutta $4^{\text {th }}$ order method were $2.08 \mathrm{~g} / \mathrm{L}$ for $K_{M}$ and $0.04 \mathrm{~g} / \mathrm{L}$ for $V_{\max }$. The application of Michaelis-Menten equation describes the enzyme kinetic very well. From the kinetic analysis, it showed the good agreement between the result obtained and the predictions model in the production of methanol using PME enzyme. This conclusion also validated the result obtained by the statistical significance.

\section{Acknowledgment}

The author wishes to acknowledge the Universiti Malaysia Pahang for funding the project under grant RDU170346.

\section{Nomenclatures}

DE : Degree of esterification

E : Enzyme

ES : Enzyme substrate complex

$\mathrm{K}_{\mathrm{M}} \quad$ : Michaelis-Menten constant

ODE : Ordinary differential equation

$\mathrm{P} \quad$ : Product

PME : Pectin metyl estetrase

$\mathrm{R}^{2} \quad$ : Correlation coefficient

$\mathrm{S} \quad$ : Substrate

$\mathrm{V}_{\max } \quad$ : Maximum rate of reaction

\section{References}

[1] Esfahanian, M., Ghorbanfarahi, A.H., Ghoreyshi, A.A., Najafpour, G., Younesi, H., Ahmad, A.L. (2012). Enhanced Bioethanol Production in Batch Fermentation by Pervaporation Using a PDMS Membrane Bioreactor. International Journal of Engineering Transactions B: Applications, 25(4): 249-258.

[2] Sultana, B., Anwar, F., Ashraf, M. (2009). Effect of Extraction Solvent/Technique on the Antioxidant Activity of Selected Medicinal Plant Extracts. Molecules, 14: 2167-2180.

[3] Hang, Y.D., Woodams, E.E. (2008). Methanol content of grappa made from New York grape pomace. Bioresource Technology, 99: 39233925 .

[4] Hosseinpour, M.N., Najafpour, G.D., Younesi, H., Khorrami, M., Vaseghi, Z. (2012). Lipase Production in Solid State Fermentation Using Aspergillus niger: Response Surface Methodology. International Journal of Engineering Transactions B: Applications, 25(3): 151-159.

[5] Golicnik, M. (2011). Evaluation of enzyme kinetic parameters using explicit analytic approximations to the solution of the MichaelisMenten equation. Biochemical Engineering Journal, 53: 234-238.

[6] Carvalho, M.L., Sousa, Jr.R., RodríguezZuniga, U.F., Suarez, C.A.G., Rodrigues, D.S., Giordano, R.C., Giordano, R.L.C. (2013). Kinetic study of the enzymatic hydrolysis of sugarcane bagasse. Brazilian Journal of Chemical Engineering, 30(3): 437-447.

[7] Shuler, M.L., Kargi, F. (2002). Bioprocess Engineering: Basic Concepts, 2nd Edition. Prentice Hall, New Jersey.

[8] Vivian, D., Polli, J.E. (2014). Mechanistic interpretation of conventional MichaelisMenten parameters in a transporter system. European Journal of Pharmaceutical Sciences, 64: 44-52.

[9] Mishra, A., Kumar, S. (2009). Kinetic studies of laccase enzyme of Coriolus versicolor MTCC 138 in an inexpensive culture medium. Biochemical Engineering Journal, 46: 252-256.

[10] Wang, Q. (2006). Biomethanol Conversion From Sugar Beet Pulp With Pectin Methyl Esterase. Thesis submitted to the Faculty of the Graduate School of the University of Maryland, College Park.

[11] Simsek, S., Yemenicioglu, A. (2010). Commercially suitable pectin methylesterase from Valencia orange peels. Turk J. Agric., 34: 109119.

[12] Carbonell, J.V, Cotreras, P., Carbonell, L., Navarro, J.L. (2006). Pectin methylesterase activity in juices from mandarins, oranges and hybrids. Eur. Food Res. Technol., 222: 83-87.

[13] Gonzalez, S.L., Lima, R.C.A., Carneiro, E.B.B., Almeida, M.M.D., Rosso, N.D. (2008). Pectin methylesterase activity determined by different methods and thermal inactivation of exogenous pme in mango juice. Ciência $e$ Agrotecnologia, 35(5): 987-994.

[14] Parpinello, G.P., Andrea Versari, A. (2000). A Simple High-Performance Liquid Chromatography Method for the Analysis of Glucose, Glycerol, and Methanol in a Bioprocess. 
Journal of Chromatographic Science, 38(6): 259-261.

[15] Hosseini, S.S., Khodaiyan, F., Yarmand, M.S. (2016). Optimization of microwave assisted extraction of pectin from sour orange peel and its physicochemical properties. Carbohydrate Polymers, 140: 59-65.

[16] Oikawa, P.Y., Li, L., Timko, M.P., Mak, J.E., Lerdau, M.T. (2011). Short term changes in methanol emission and pectin methylesterase activity are not directly affected by light in Lycopersicon esculentum. Biogeosciences, 8: 1023-1030.

[17] Yoo, Y.H., Lee, S., Kim, Y., Kim, K.O., Kim, Y.S., Yoo, S.H. (2009). Functional characterization of the gels prepared with pectin methylesterase (PME)-treated pectins. Int. J. Biol. Macromol., 45(3) : 226-230.

[18] Linskens, H.F., Jackson, J.F. (2012). Modern Method of Plant analysis in Plant Cell wall Analysis, German: Springer-Verlag Berlin Heirdeberg.

[19] Kohli, P., Kalia, M., Gupta, R. (2015). Pectin Methylesterases: A Review. J Bioprocess Biotech., 5: 1-7.

[20] Saha, P., Khan, M.R., Deb, T.K., Majumdar, S., Alam, F., Sarker, N.C. (2012) Enzymatic Hydrolysis of Rice Straw to Fermentable Sugar: Kinetic Study. Journal of Chemical Engineering, 27(2): 20-24.
[21] Kakkar, T., Boxenbaum, H., Mayersohn, M. (1999). Estimation of $\mathrm{Ki}$ in a competitive enzyme-inhibition model: comparisons among three methods of data analysis drug metabolism and disposition. Drug Metabolism and Disposition, 27(6): 756-762.

[22] Dhatt, S., Bhattacharyya, K. (2017). The Michaelis-Menten kinetics and errors in estimated reaction constants: A reappraisal. Journal of the Indian Chemical Society, 94: 1267-1278

[23] Isotani, S., Pontuschka, W.M., Isotani, S. (2012). An Algorithm to Optimize the Calculation of the Fourth Order Runge-Kutta Method Applied to the Numerical Integration of Kinetics Coupled Differential Equations. Applied Mathematics, 3: 1583-1592.

[24] Liburdi, K., Benucci, I., Palumbo, F., Esti, M. (2016). Lysozyme immobilized on chitosan beads: Kinetic characterization and antimicrobial activity in white wines. Food Control, 63: 46-52.

[25] Dixit, S., Upadhyay, S.K., Singh, H., Pandey, B., Chandrashekar, K., Verma, P.C. (2013). Pectin Methylesterase of Datura species, purification, and characterization from Datura stramonium and its application. Plant Signaling \& Behavior, 8(10): 2568-2569.

[26] Luzio, G.A., Cameron, R.G. (2008). Demethylation of a model homogalacturonan with the salt-independent pectin methylesterase from citrus: Part II. Structure-function analysis. Carbohydrate Polymers, 71: 300-309. 